\title{
Analysis and Minimization of Output Current Ripple of Multiphase Carrier-Based PWM Inverters
}

\author{
Pekik Argo Dahono \\ School of Electrical Engineering and Informatics, Institute of Technology Bandung, \\ J1. Ganesa No. 10, Bandung 40132, Indonesia \\ Tel. 62-22-2503315, Fax. 62-22-2508132 \\ Email pekik@konversi.ee.itb.ac.id
}

\begin{abstract}
Analysis and minimization of output current ripple of multiphase carrier-based PWM inverters are presented in this paper. Analytical expression of rms value of output current ripple of multiphase PWM inverters as a function of the reference signal is first derived. Based on this expression, it is shown that a pure sinusoidal signal is the optimum reference signal that results in minimum output current ripple. Different to three-phase PWM inverters, injection of harmonics into the sinusoidal reference signal is neither necessary nor useful. The rms values of output current ripple of 5-, 7-, and 9-phase PWM inverters under various reference signals are compared. Experimental results are included to show the validity of the analysis method.
\end{abstract}

Keywords: Multiphase; PWM Inverter; Ripple; AC drive.

\section{$1 \quad$ Introduction}

Multiphase (number of phase higher than three) technique to improve the power density and reliability of ac motor drives is gaining interest in the recent decades [1]. Various control methods for multiphase ac drives were proposed. Different to three-phase PWM inverters, suitable PWM techniques for multiphase PWM inverters have not been developed very well [2-5]. In the case of three-phase PWM inverter, it has been shown that a sinusoidal signal plus twenty-five percent third harmonic is the optimum reference signal that results in minimum output current ripple or harmonics [6-8]. Third harmonic injection is also useful to increase the maximum output voltage of three-phase PWM inverters. No paper has shown what the optimum reference signal for multiphase PWM inverters is. Is twenty-five percent third harmonic also the optimum injected harmonic signal?

In this paper, analysis and minimization of the output current ripple of multiphase PWM inverters are presented. Analytical expression of the rms value of output current ripple of multiphase PWM inverters as a function of the modulation signal is first derived. Based on this expression, it is shown that a pure sinusoidal signal is the optimum reference signal that results in minimum

Received May $19^{\text {th }}, 2009$, Revised August $28^{\text {th }}, 2009$. Accepted for publication November $12^{\text {th }}, 2009$. 
output current ripple. Different to three-phase PWM inverters, injection of harmonics into the sinusoidal reference signal is neither necessary nor useful. The rms values of output current ripple of 5-, 7-, and 9-phase PWM inverters under various reference signals are compared. Experimental results are included to show the validity of the analysis method.

\section{$2 \quad$ Multiphase PWM Inverters}

A multiphase PWM inverter is defined as an inverter with a phase number higher than three. The scheme of multiphase PWM inverters is shown in Figure 1. The load is assumed to be connected in polygon connection. If the actual load is connected in star connection, a polygon equivalent connection can be found easily. Each phase of load is represented as a series connection of a resistance, an inductance, and a sinusoidal emf. The dc voltage source of the inverter is assumed to be a ripple free constant dc voltage source. The center-tap in the $\mathrm{dc}$ voltage source does not really exist but it is used only for analysis purpose. The switching devices are assumed as ideal switches.

The ON-OFF signals for the switching devices are obtained by comparing a multiphase reference or modulation signal to a highfrequency triangular carrier signal. Figure 2 shows an example of sinusoidal nine-phase reference signal. If the instantaneous value of a phase reference signal is higher (lower) than the carrier signal then the associated upper (lower) switching device receives an ON signal. By using this method, the average value (average over one carrier period) of the phase-to-zero voltage will follow the reference signal. If the reference signal is sinusoidal then the average value of phase-to-zero voltage is also sinusoidal.

\section{Analysis and Minimization of Output Current Ripple}

Let us assume that the reference signal can be written as follow:

$$
\begin{aligned}
& v_{1}^{r}=k \sin (\theta)+s_{o} \\
& v_{2}^{r}=k \sin (\theta-\gamma)+s_{o} \\
& v_{3}^{r}=k \sin (\theta-2 \gamma)+s_{o} \\
& \vdots \\
& v_{N}^{r}=k \sin (\theta-(N-1) \gamma)+s_{o}
\end{aligned}
$$




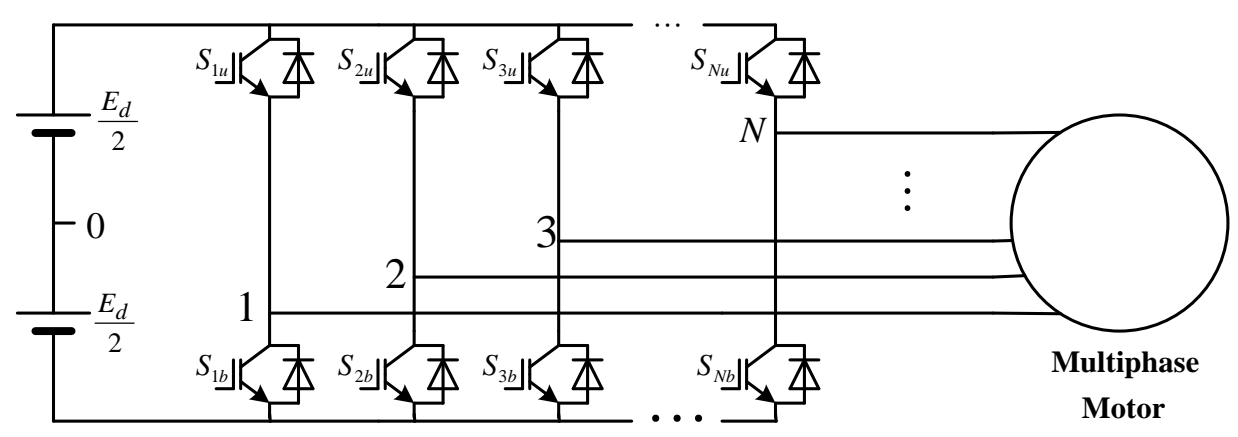

(a) Multiphase PWM inverter.

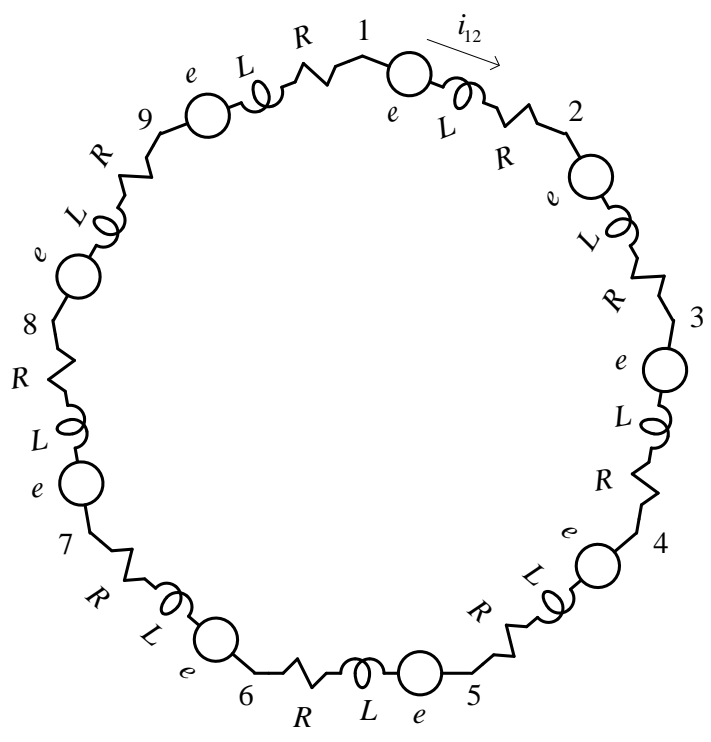

Nine phase

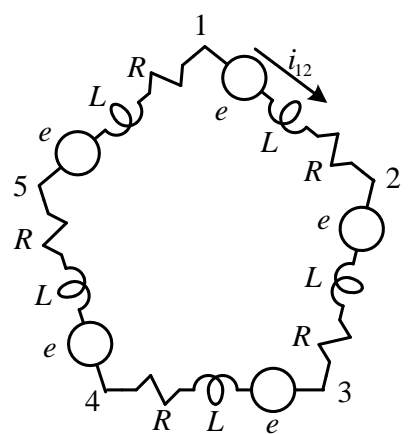

Five phase

(b) Nine-phase and five-phase load.

Figure 1 Scheme of multiphase inverter and load connections. 


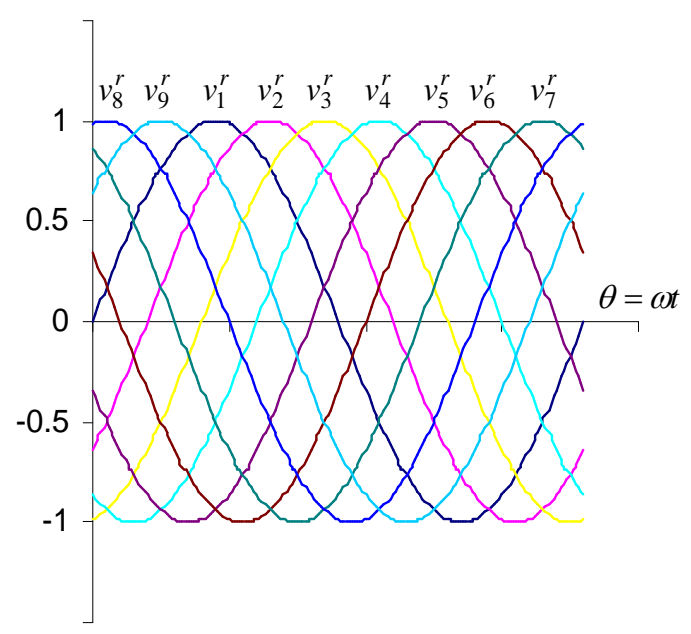

Figure 2 Nine-phase sinusoidal reference signal.

where $\gamma=2 \pi / N$ and $N$ is the number of phase $(N \geq 3)$ and $\theta=\omega t$. In (1), $s_{o}$ is an arbitrary signal that is injected into the sinusoidal reference signal. Because the same signal is injected into the phase reference signals, the phase-to-phase voltages will not be changed by this injection of arbitrary signal. The arbitrary assumption of signal $s_{o}$ is valid as long as the frequency is much lower than the carrier frequency.

Based on the circuit in Figure 1, the voltage between phases 1 and 2 can be written as:

$$
v_{12}=R i_{12}+L \frac{d i_{12}}{d t}+e_{12}
$$

If the voltage and current in the above equation are separated into the average (average over one switching cycle) and ripple components, $v_{12}=\bar{v}_{12}+\tilde{v}_{12}$ and $i_{12}=\bar{i}_{12}+\tilde{i}_{12}$, then (2) can be rewritten as

$$
\bar{v}_{12}+\tilde{v}_{12}=R\left(\bar{i}_{12}+\tilde{i}_{12}\right)+L \frac{d}{d t}\left(\overline{i_{12}}+\tilde{i}_{12}\right)+e_{12}
$$

Because the load emf is assumed sinusoidal, the load emf has no ripple component. The average and ripple components on the left hand and right hand parts of (3) must be the same, respectively, and therefore:

$$
\bar{v}_{12}=R \overline{\dot{i}_{12}}+L \frac{d \overline{\dot{i}_{2}}}{d t}+e_{12}
$$




$$
\tilde{v}_{12}=R \tilde{i}_{12}+L \frac{d \tilde{i}_{12}}{d t}
$$

The ripple voltage drop across the load resistance, $R \tilde{\dot{i}}_{12}$, is much smaller than other components in (5) and, therefore, the expression of the ripple current can be obtained as follow:

$$
\tilde{i}_{12}=\frac{1}{L} \int \tilde{v}_{12} d t=\frac{1}{L} \int\left(v_{12}-\bar{v}_{12}\right) d t
$$

Figure 3 shows the detailed waveforms of multi-phase PWM inverter over one carrier period. In order to simplify the analysis, it is assumed that amplitude of the triangular carrier signal is unity. Because the carrier frequency is much higher than the reference ones, the reference signals over one carrier period can be assumed as constants. This figure was drawn for the case when the instantaneous value of reference signal for phase 1 is higher than the one for phase 2 .

Time intervals in Figure 3 can be obtained as below:

$$
\begin{aligned}
& \frac{T_{o}}{T_{s}}=\frac{1}{4}-\frac{1}{4} v_{1}^{r} \\
& \frac{T_{1}}{T_{s}}=\frac{1}{4}\left(v_{1}^{r}-v_{2}^{r}\right)=\frac{1}{4} v_{12}^{r} \\
& \frac{T_{2}}{T_{s}}=\frac{1}{4}+\frac{1}{4} v_{2}^{r}
\end{aligned}
$$

where

$$
\begin{aligned}
& v_{12}^{r}=v_{1}^{r}-v_{2}^{r}=C k \sin (\theta+\alpha) \\
& T_{s}=1 / f_{s} \\
& C=\sqrt{2(1-\cos \gamma)} \\
& \alpha=\frac{\pi-\gamma}{2}
\end{aligned}
$$

and $f_{s}$ is the switching or carrier frequency. Based on (6) and the output voltage waveform in Figure 3, the output current ripple over one switching period can be written as given by (14). The waveform of the current ripple over one carrier period is also shown in Figure 3. 


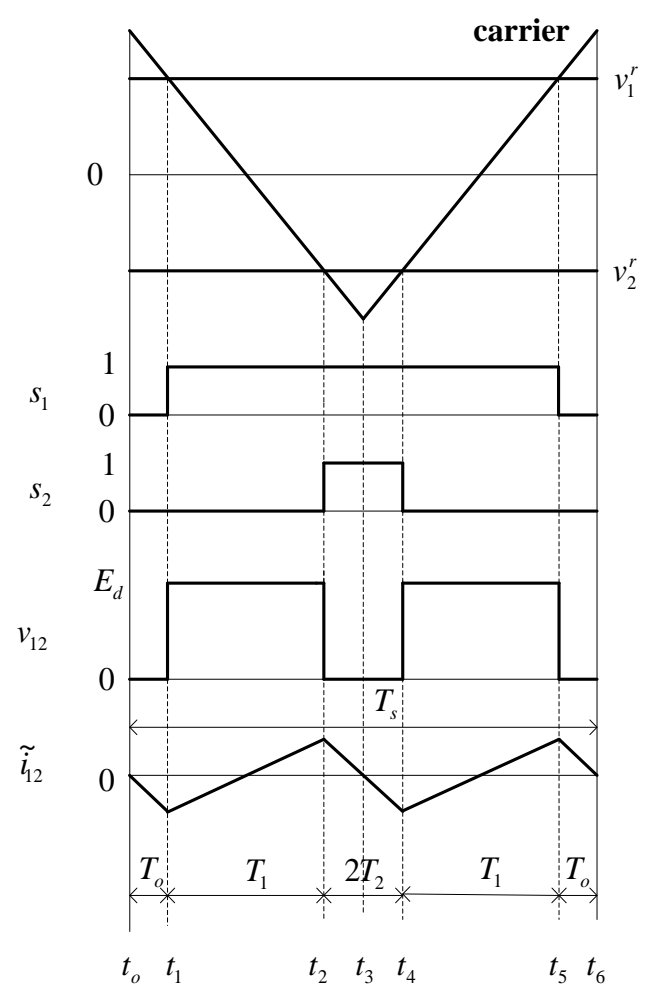

Figure 3 Detailed output waveforms over one switching period.

$$
\tilde{i}_{12}=\left\{\begin{array}{cc}
-\frac{\bar{v}_{12}}{L}\left(t-t_{o}\right) & \text { for } t_{o} \leq t \leq t_{1} \\
-\frac{\bar{v}_{12}}{L} T_{o}+\frac{E_{d}-\bar{v}_{12}}{L}\left(t-t_{1}\right) & \text { for } t_{1} \leq t \leq t_{2} \\
-\frac{\bar{v}_{12}}{L}\left(t-t_{3}\right) & \text { for } t_{2} \leq t \leq t_{4} \\
-\frac{\bar{v}_{12}}{L} T_{3}+\frac{E_{d}-\bar{v}_{12}}{L}\left(t-t_{4}\right) & \text { for } t_{4} \leq t \leq t_{5} \\
-\frac{\bar{v}_{12}}{L}\left(t-t_{6}\right) & \text { for } t_{5} \leq t \leq t_{6}
\end{array}\right.
$$

In (14),

$$
\bar{v}_{12}=E_{d} \frac{T_{1}}{T_{o}+T_{1}+T_{2}}=\frac{E_{d}}{2} v_{12}^{r}
$$


is the average value of voltage between phases 1 and 2 . The mean square value of the output current ripple over one carrier period can be obtained as

$$
\begin{aligned}
\tilde{I}_{12}^{2} & =\frac{1}{T_{s}} \int_{t_{o}}^{t_{o}+T_{s}} \tilde{i}_{12}^{2} d t \\
& =\frac{E_{d}}{T_{s} L^{2}}\left[v_{12}^{r 2} \frac{T_{o}^{3}}{3}+v_{12}^{r 2} T_{o}^{2} T_{1}-v_{12}^{r}\left(2-v_{12}^{r}\right) T_{o} T_{1}^{2}+\left(2-v_{12}^{r}\right)^{2} \frac{T_{1}^{3}}{3}+v_{12}^{r 3} \frac{T_{2}^{3}}{3}\right]
\end{aligned}
$$

If (1) is substituted into (7)-(9) and the results are substituted into (16) then the mean square value of output current ripple over one switching period as a function of $s_{o}$ can be obtained as:

$$
\tilde{I}_{12}^{2}=\frac{K^{2}}{384} v_{12}^{r 2} \times\left\{2-2 k C \sin (\theta+\alpha)+3 k^{2}+6 s_{o}^{2}+6 D k s_{o} \sin (\theta-\beta)\right\}
$$

where

$$
\begin{aligned}
K & =\frac{E_{d}}{L f_{s}} \\
D & =\sqrt{2(1+\cos \gamma)} \\
\beta & =\gamma / 2
\end{aligned}
$$

If only the terms containing $s_{o}$ are considered, the modified mean square value of current ripple can be obtained from (17) as follow:

$$
\tilde{I}_{12}^{\prime 2}=\frac{K^{2}}{384} v_{12}^{r 2}\left\{6 s_{o}^{2}+6 D k s_{o} \sin (\theta-\beta)\right\}
$$

By using the same method, the modified mean square values of current ripple for other phases can be obtained as:

$$
\begin{aligned}
& \tilde{I}_{23}^{\prime 2}=\frac{K^{2}}{384} v_{23}^{r 2}\left\{6 s_{o}^{2}+6 D k s_{o} \sin (\theta-\beta-\gamma)\right\} \\
& \tilde{I}_{34}^{\prime 2}=\frac{K^{2}}{384} v_{34}^{r^{2}}\left\{6 s_{o}^{2}+6 D k s_{o} \sin (\theta-\beta-2 \gamma)\right\} \\
& \tilde{I}_{45}^{\prime 2}=\frac{K^{2}}{384} v_{45}^{r^{2}}\left\{6 s_{o}^{2}+6 D k s_{o} \sin (\theta-\beta-3 \gamma)\right\} \\
& \vdots \\
& \tilde{I}_{N 1}^{\prime 2}=\frac{K^{2}}{384} v_{N 1}^{r^{2}}\left\{6 s_{o}^{2}+6 D k s_{o} \sin [\theta-\beta-(N-1) \gamma]\right\}
\end{aligned}
$$


where

$$
\begin{aligned}
& v_{23}^{r}=k C \sin (\theta+\alpha-\gamma) \\
& v_{34}^{r}=k C \sin (\theta+\alpha-2 \gamma) \\
& v_{45}^{r}=k C \sin (\theta+\alpha-3 \gamma) \\
& \vdots \\
& v_{N 1}^{r}=k C \sin [\theta+\alpha-(N-1) \gamma]
\end{aligned}
$$

The total modified output current ripple is defined as

$$
\tilde{I}_{\text {tot }}^{\prime 2}=\tilde{I}_{12}^{\prime 2}+\tilde{I}_{23}^{\prime 2}+\tilde{I}_{34}^{\prime 2}+\cdots+\tilde{I}_{N 1}^{\prime 2}
$$

If (21) and (22) are substituted into (24) then the following is obtained:

$$
\tilde{I}_{t o t}^{\prime 2}=\frac{K^{2}}{768}\left(6 N s_{o}^{2}\right) \quad \text { for } N \neq 3
$$

If $N=3$, the total modified current ripple is

$$
\tilde{I}_{\text {tot }}^{\prime 2}=\frac{K^{2}}{768}\left[18 s_{o}^{2}-9 k s_{o} \sin (3 \theta)\right]
$$

The optimum injected signal can be obtained by solving the following equation:

$$
\frac{d \tilde{I}_{t o t}^{\prime 2}}{d s_{o}}=0
$$

The results are

$$
s_{o}=0
$$

for $N \neq 3$, and

$$
s_{o}=\frac{k}{4} \sin (3 \theta)
$$

for $N=3$. Thus, third harmonic injection can be used to reduce the output current ripple if and only if the number of phase is three. For higher number of phase, harmonic injection into the sinusoidal reference signal is neither necessary nor useful to reduce the output current ripple. It should be noted that the result as shown by (29) is the same as the result in [6-8].

The root-mean-square (rms) value of the mean square value of the current ripple through phase 12 over one fundamental output period can be obtained as: 


$$
\tilde{I}_{12 r m s}=\left[\frac{1}{\pi} \int_{-\alpha}^{\pi-\alpha} \tilde{I}_{12}^{2} d \theta\right]^{1 / 2}
$$

Under pure sinusoidal reference signal, the rms values of current ripples of all phases are the same regardless the number of phase. Under this reference signal, the rms value of phase current ripple is

$$
\tilde{I}_{r m s}=\frac{K k C}{16 \sqrt{3}}\left[2-\frac{16 C}{3 \pi} k+\frac{3}{2} k^{2}\right]^{1 / 2}
$$

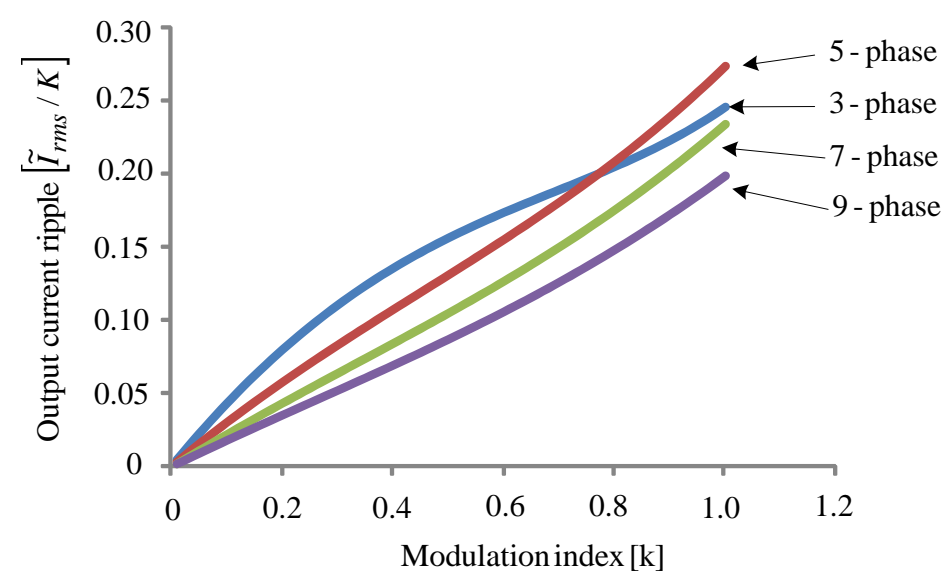

Figure 4 Output current ripple for several phase numbers.

Figure 4 shows the rms value of output current ripple of three-, five-, seven-, and nine-phase PWM inverters under sinusoidal modulation signal. In [9], it was shown that a harmonic signal injection can be used to increase the maximum modulation index of multiphase carrier-based PWM inverters. The injected harmonic signal is (for $\mathrm{N}>3$ ):

$$
s_{o}=-\frac{k}{N} \sin \left(\frac{\pi}{2 N}\right) \sin (N \theta)
$$

Under this harmonic injection, the maximum modulation index is increased into:

$$
k_{\text {max }}=\frac{1}{\cos \left(\frac{\pi}{2 N}\right)}
$$

If (32) is substituted into (17) and the result is substituted into (30) and performing the integration then the following is obtained: 


$$
\tilde{I}_{r m s}=\frac{K k C}{16 \sqrt{3}}\left[2-\frac{16 C}{3 \pi} k+k^{2}\left(\frac{3}{2}+\frac{3 \sin ^{2}(\pi / 2 N)}{N^{2}}\right)\right]^{1 / 2}
$$

If the phase number is higher than three, the maximum modulation index is increased by the harmonic injection but the output current ripple is increased.

\section{$4 \quad$ Experimental Result and Validity Limits}

A small five-phase PWM inverter was constructed to verify the analysis method. The inverter switching devices were implemented by using power MOSFETs. A stalled five-phase induction motor was used as the load. The locked resistance and inductance are $2.2 \mathrm{ohm}$ and $6 \mathrm{mH}$, respectively. The switching frequency of the inverter was fixed at $2000 \mathrm{~Hz}$. The fundamental frequency of the output voltage was fixed at $50 \mathrm{~Hz}$. The dc input voltage is fixed at $60 \mathrm{Vdc}$.

Figure 5 shows the output current under sinusoidal reference signal. This figure shows that the output current waveform is almost purely sinusoidal.

In order to measure the output current ripple, the output current waveform is stored in a digital oscilloscope. The stored data is then processed by using a computer to determine the ripple content. Figure 6 shows the experimental and calculated results of output current ripples under sinusoidal reference signal. This result shows clearly the validity of the proposed analysis method.

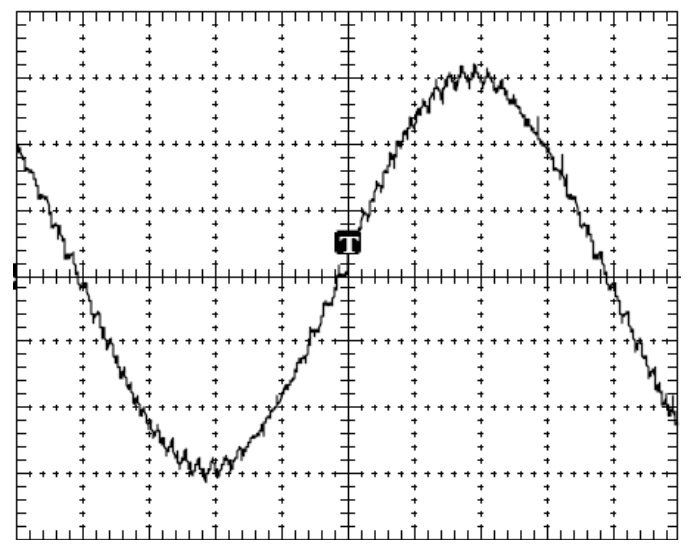

Ver : $2.5 \mathrm{~A} / \mathrm{div}$ Hor : $2.5 \mathrm{~ms} / \mathrm{div}$

Figure 5 Output current waveform of five-phase PWM inverter under sinusoidal reference signal. 


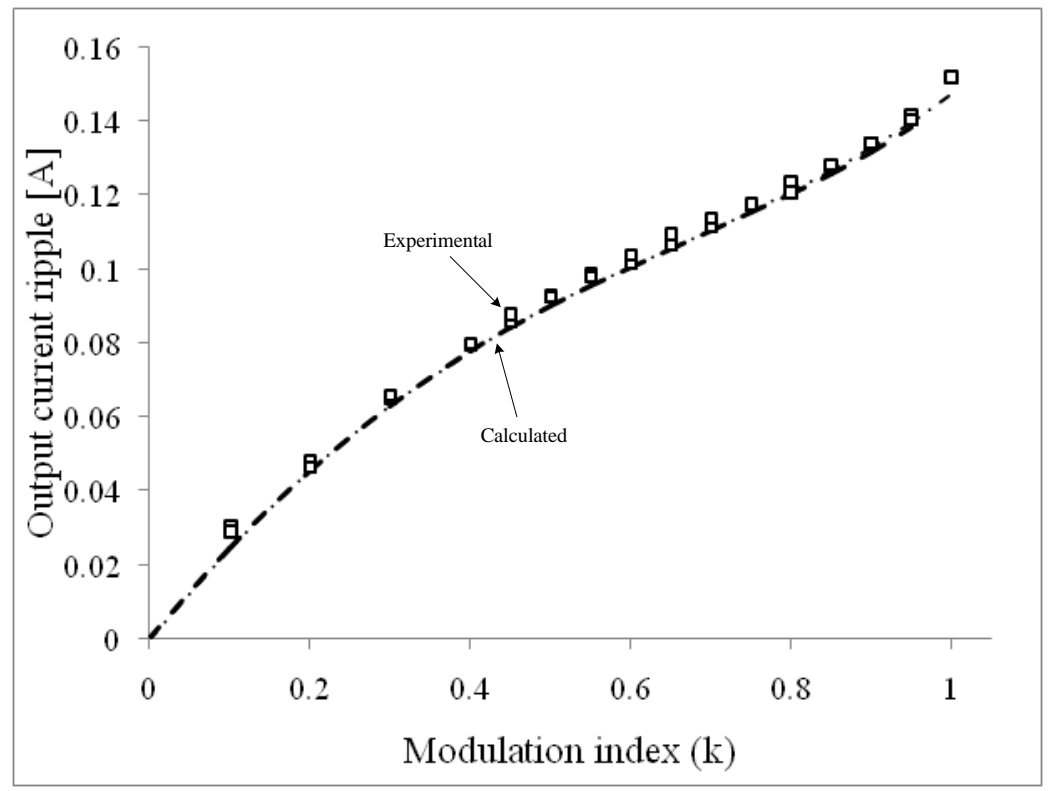

Figure 6 Experimental and calculated results.

In order to determine the validity limits of the proposed analysis method, an extensive simulation has been done by the author. In general, the proposed method results in accurate results (error less than 5\%) as long as the followings are fulfilled:

1. The ratio of the carrier frequency to the reference frequency is higher than 10.

2. The ratio of load time constant $(\mathrm{L} / \mathrm{R})$ to the carrier period is higher than 10 .

3. The dc source ripple is less than $5 \%$

4. The load unbalance factor is less than $2 \%$.

\section{Conclusion}

Analysis and minimization of output current ripple of multiphase PWM inverters have been presented in this paper. It is shown that a pure sinusoidal reference signal is the optimum reference signal that results in minimum output current ripple. Different to three-phase PWM inverters, the maximum modulation index cannot be increased by harmonic signal injection without sacrificing the output current ripple. Experimental results have shown the validity of the proposed analysis method. Extension of this work to nonsinusoidal emf is under investigation. 


\section{Acknowledgment}

Part of this work is supported by Riset Unggulan ITB 2007. The author wish to thank Deni, former student of ITB, for his assistance during the experiment.

\section{References}

[1] Delarue, P., Bouscayrol, A. \& Semail, E., Generic Control Method of Multileg Voltage-Source-Converters for Fast Practical Implementation, IEEE Trans. Power Electr, 18(2), pp. 517-526, March 2003.

[2] Kelly, J.W., Strangas, E.G. \& Miller, J.M., Multiphase Space Vector Pulse Width Modulation, IEEE Trans. Energy Conv., 18(2), pp. 259-264, June 2003.

[3] Ryu, H.M., Kim, J.H. \& Sul, S.K., Analysis of Multiphase Space-Vector Pulse Width Modulation Based on Multiple d-q Spaces Concept, IEEE Trans. Power Electr., 20(6), pp. 1364-1371, Nov. 2005.

[4] Grandi, G., Serra, G. \& Tani, A., General Analysis of Multiphase Systems Based on Space Vector Approach, Proc. EPE Power Electr. Motion Con., Slovenia, 834-840, 2006.

[5] Levi, E., Multiphase Electric Machines for Variable-Speed Applications, IEEE Trans. Ind. Electr., 55(5), pp. 1893-1909, May 2008.

[6] Bowes, S.R. \& Midoun, A., Suboptimal Switching Strategies for Microprocessor-Controlled PWM Inverter Drives, IEE Proc. B, 132, 133-148, May 1985.

[7] Kolar, J.W., Ertl, H. \& Zach, F.C., Influence of the Modulation Method on the Conduction and Switching Losses, IEEE Trans. Ind. Appl., 27(6), pp. 1063-1075, Nov./Dec. 1991.

[8] Dahono, P.A., Sato, Y. \& Kataoka, T., Analysis and Minimization of Harmonics in the Input and Output Sides of PWM Inverters, IEE Japan Trans. Ind. Appl., 115, pp. 641-650, May 1995.

[9] Iqbal, A., Levi, E., Jones, M. \& Vukosavic, S.N., Generalized Sinusoidal PWM with Harmonic Injection for Multiphase VSIs, Proc. $17^{\text {th }}$ IEEE Power Electronics Specialists Conference, Korea, 2871-2877, 2006. 